\title{
(2) OPEN ACCESS \\ Anticardiolipin and other antiphospholipid antibodies in critically ill COVID-19 positive and negative patients
}

\author{
Uriel Trahtemberg (1) , ${ }^{1}$ Robert Rottapel, ${ }^{2,3}$ Claudia C Dos Santos, ${ }^{1,4,5}$ \\ Arthur S Slutsky, ${ }^{4,5}$ Andrew Baker, ${ }^{1,4,5}$ Marvin J Fritzler (1) ${ }^{6}$
}

\section{Handling editor Josef $S$ \\ Smolen \\ - Additional supplemental material is published online only. To view, please visit the journal online (http://dx.doi. org/10.1136/annrheumdis- 2021-220206)}

For numbered affiliations see end of article.

\section{Correspondence to} Professor Marvin J Fritzler, Medicine, University of Calgary Cumming School of Medicine, Calgary, Canada;

fritzler@ucalgary.ca

Received 20 February 2021 Revised 16 March 2021

Accepted 7 April 2021 Published Online First 26 April 2021

\section{Linked}

- http://dx.doi.org/10.1136/ annrheumdis-2021-220520

\section{Check for updates}

(C) Author(s) (or their employer(s)) 2021. Re-use permitted under CC BY-NC. No commercial re-use. See rights and permissions. Published by BMJ.

To cite: Trahtemberg $U$, Rottapel R, Dos Santos CC, et al. Ann Rheum Dis 2021:80:1236-1240.

\section{ABSTRACT}

Background Reports of severe COVID-19 being associated with thrombosis, antiphospholipid antibodies (APLA), and antiphospholipid syndrome have yielded disparate conclusions. Studies comparing patients with COVID-19 with contemporaneous controls of similar severity are lacking.

Methods 22 COVID- $19^{+}$and 20 COVID-19- patients with respiratory failure admitted to intensive care were studied longitudinally. Demographic and clinical data were obtained from the day of admission. APLA testing included anticardiolipin (aCL), anti-ß2glycoprotien 1 ( $\beta 2 \mathrm{GP} 1)$, antidomain $1 \beta 2 \mathrm{GP} 1$ and antiphosphatidyl serine/prothrombin complex. Antinuclear antibodies (ANAs) were detected by immunofluorescence and antibodies to cytokines by a commercially available multiplexed array. Analysis of variance was used for continuous variables and Fisher's exact test was used for categorical variables with $\alpha=0.05$ and the false discovery rate at $\mathrm{q}=0.05$.

Results APLAs were predominantly $\operatorname{lgG} \mathrm{aCL}(48 \%)$, followed by IgM $(21 \%)$ in all patients, with a tendency towards higher frequency among the COVID-19+. $\mathrm{aCL}$ was not associated with surrogate markers of thrombosis but IgG aCL was strongly associated with worse disease severity and higher ANA titres regardless of COVID-19 status. An association between $\mathrm{aCL}$ and anticytokine autoantibodies tended to be higher among the COVID-19+

Conclusions Positive APLA serology was associated with more severe disease regardless of COVID-19 status. Trial registration number NCT04747782

\section{INTRODUCTION}

Antiphospholipid antibodies (APLAs) are biomarkers of a spectrum of clinical features observed in antiphospholipid syndrome (APS). ${ }^{1}$ Features of APS include venous and arterial thrombosis involving multiple organs and having various presentations. ${ }^{1}$ APLAs that are components of APS criteria include $\operatorname{IgG}$ and/or IgM anticardiolipin (aCL), anti- $\beta 2$-glycoprotein 1 (anti- $\beta 2 \mathrm{GP} 1$ ) and the 'lupus anticoagulant' (LAC). ${ }^{2}$ Other non-criteria APLA such as antiphosphatidylserine/prothrombin (PS/PT) complex, anti-PT and antidomain 1 of 32-GP1 have also found a diagnostic niche in APS. ${ }^{34}$

One of the salient features of COVID-19 is the development of thrombotic events associated with severe morbidity and mortality. ${ }^{5-8}$ In the context of systemic inflammation and dysregulated immunity, ${ }^{9}$

\section{Key messages}

What is already known about this subject?

- COVID-19 is associated with coagulopathy and high morbidity and mortality.

- COVID-19 shares some of these clinical features with antiphospholipid syndrome.

- Reports of an association of antiphospholipid antibodies with high-risk COVID-19 have yielded disparate conclusions, but they lacked longitudinal follow-up and control groups of similar severity.

What does this study add?

- Antiphospholipid syndrome serology assessed longitudinally was predominantly anticardiolipin IgG autoantibodies, in $48 \%$ of patients.

- Anticardiolipin serology was associated with worse disease severity in both COVID-19 positive and negative patients.

How might this impact on clinical practice or future developments?

- The use of antiphospholipid antibodies tests in the COVID-19 clinical setting needs to be taken in context; whereas they are associated with more serve disease, they do not discriminate between COVID-19 positive and negative patients.

some reports have linked APLA to these thromboses, ${ }^{10}{ }^{11}$ severe COVID-19 $9^{6} 12$ and release of neutrophil extracellular traps. ${ }^{6}$ However, APLAs are also described in a variety of other infectious diseases ${ }^{13}$ and critically ill patients have high rates of thromboembolism that were not linked to APS or APLA $^{14}$ (critically reviewed in ref. 15). Therefore, the association of COVID-19 with APLA and their potential pathogenic role ${ }^{16}$ has not been clearly demonstrated due to the lack of contemporaneous, COVID-19 negative controls. Here, we compare the prevalence and clinical correlations of APLA in patients with severe COVID-19 as compared with contemporaneous non-COVID19 patients with similar clinical characteristics.

\section{METHODS}

Informed consent was obtained from all patients or their legal surrogates. Inclusion criteria were age $\geq 18$ years, admission to intensive care unit (ICU) 
Table 1 Patient demographics, clinical and autoantibody status

\begin{tabular}{|c|c|c|c|c|}
\hline & Cohort & All & COVID $^{+}$ & COVID $^{-}$ \\
\hline & $\mathrm{N}$ & 42 & 22 & 20 \\
\hline Age & Mean $(\mathrm{Cl})$ & $58.2(62.7$ to 54.1$)$ & $60.9(66.6$ to 55.3$)$ & 55.7 (62 to 48.7$)$ \\
\hline Sex & $\mathrm{N}$ male $(\%)$ & $29 / 42(69)$ & $17 / 22(77)$ & $12 / 20(60)$ \\
\hline Censored? & $\mathrm{N}(\%)$ & $5 / 42(12)$ & $4 / 22(18)$ & $1 / 20(5)$ \\
\hline No of days before censoring & Mean $(\mathrm{Cl})$ & 39.4 (59.4 to 19.4$)$ & 44.3 (66.2 to 22.3$)$ & 20 (NA) \\
\hline Days from symptom onset to ICU & Mean $(\mathrm{Cl})$ & 6 (8.3 to 3.7 ) & 7.5 (9.9 to 5.2$)$ & $4.2(8.5$ to 0$)$ \\
\hline APACHE II on ICU admission & Mean $(\mathrm{Cl})$ & 25.3 (27.6 to 22.9$)$ & 23.7 (27 to 20.4 ) & 27 (30.5 to 23.5$)$ \\
\hline Mean of SOFA score for first 3 days & Mean $(\mathrm{Cl})$ & 9.6 (10.7 to 8.5$)$ & 9.3 (11 to 7.7$)$ & $9.9(11.6$ to 8.3$)$ \\
\hline Mean of SOFA score for first 7 days & Mean $(\mathrm{Cl})$ & $8.9(10.1$ to 7.8$)$ & 9.1 (11 to 7.3$)$ & $8.7(10.3$ to 7.2$)$ \\
\hline ICU days (censored) & Mean $(\mathrm{Cl})$ & 14.1 (17.3 to 10.8$)$ & $14.2(20.5$ to 7.8$)$ & 14 (16.9 to 11.1$)$ \\
\hline Death in ICU & $\mathrm{N}(\%)$ & $13 / 42(31)$ & $7 / 22(32)$ & $6 / 20(30)$ \\
\hline Mechanical ventilation days (censored) & Mean $(\mathrm{Cl})$ & $14.4(18.9$ to 10$)$ & 16.8 (25.1 to 8.6$)$ & $11.8(14.9$ to 8.7$)$ \\
\hline Total days of ventilation rescue measures & Mean $(\mathrm{Cl})$ & $2.9(4.3$ to 1.4$)$ & 4.4 (7 to 1.8$)$ & $1.2(2$ to 0.4$)$ \\
\hline Therapeutic anticoagulation used & $\mathrm{N}(\%)$ & $8 / 42(19)$ & $3 / 22(14)$ & $5 / 20(25)$ \\
\hline Mean platelet count & Mean $(\mathrm{Cl})$ & 239 (269 to 209) & 264 (313 to 214) & $212(245$ to 179$)$ \\
\hline Mean platelet to neutrophil ratio & Mean $(\mathrm{Cl})$ & $35.2(42$ to 28.4$)$ & 38.7 (48.4 to 29$)$ & 31.4 (41.6 to 21.2$)$ \\
\hline $\mathrm{aCL} \lg G$ & $\mathrm{~N}(\%)$ & $20 / 42(48)$ & $13 / 22(59)$ & $7 / 20(35)$ \\
\hline $\mathrm{aCL} \lg \mathrm{M}$ & $\mathrm{N}(\%)$ & 9/42 (21) & $7 / 22(32)$ & $2 / 20(10)$ \\
\hline Anti- $\beta 2$ GPI lgG & $\mathrm{N}(\%)$ & 0 & 0 & 0 \\
\hline Anti- $\beta 2 \mathrm{GPI} \lg \mathrm{M}$ & $\mathrm{N}(\%)$ & 0 & 0 & 0 \\
\hline Anti-domain $1 \beta 2 \mathrm{GP} 1 \mathrm{lgG}$ & $\mathrm{N}(\%)$ & 0 & 0 & 0 \\
\hline Anti-PS/PT IgG & $\mathrm{N}(\%)$ & 0 & 0 & 0 \\
\hline Anti-PS/PT IgM & $\mathrm{N}(\%)$ & $1 / 42(2)$ & 1/22 (5) & 0 \\
\hline
\end{tabular}

The data were censored on 31 May 2020. Days from symptom onset were self-reported by the patients or their representatives. The SOFA score was performed daily for all patients; the average was calculated for the first 3 and 7 days in the ICU for each patient, and the mean of those averages are reported. For patients who underwent tracheostomy, mechanical ventilation days are counted until successfully weaned from ventilatory support for 24 hours. Rescue measures included use of paralytics, proning and inhaled NO (counted additively if more than one intervention used in the same day). The clinical outcomes were measured for up to 3 months. All the serologies were tested longitudinally and are reported for the first 10 days from admission to the ICU (for standardisation among patients). There was no statistically significant difference between $\mathrm{COVID}^{+}$and COVID- patients for all variables, using ANOVA for continuous variables and Fisher's exact test for categorical variables at $\alpha=0.05$, followed by the false discovery rate at $\mathrm{q}=0.05$.

aCL, anticardiolipin; ANOVA, analysis of variance; APACHE, Acute Physiology and Chronic Health Evaluation (score); $\beta 2$ GP1, beta two glycoprotein I; ICU, intensive care unit; PS/ PT, phosphatidyl serine/prothrombin complex; SOFA, sequential organ failure assessment (score).

with acute respiratory failure. Exclusion criteria were inability to ascertain the primary outcome or obtain a baseline blood sample, and SARS-CoV2 infection in the 4 weeks prior to admission. COVID-19 status was determined with PCR of nasopharyngeal swabs and/or endotracheal aspirates. Follow-up was 3 months post-ICU admission or hospital discharge. Primary outcome was death in the ICU. Secondary outcomes were in hospitaldeath, ICU utilisation metrics, organ dysfunction measures and severity scores. Clinical data and serum samples were collected longitudinally at days $0,1,3,5,7$ and 10; after day 10 or ICU discharge. aCL, anti- $\beta 2 \mathrm{GP} 1$ and anti-PS/PT were tested for IgG and IgM, as well as IgG anti-domain $1 \beta 2-G P 1$; all by ELISA or chemiluminescence (Inova Diagnostics, San Diego, California, USA). Analysis of variance was used for continuous variables and Fisher's exact test was used for categorical variables at $\alpha=0.05$, followed by a false discovery rate adjustment at $\mathrm{q}=0.05$. Detailed methods are available (online supplemental file), including methods for detection of anti-nuclear autoantibodies (ANA) by HEp-2 immunofluorescence assay (IFA) (Inova Diagnostics) and antigen-specific autoantibodies (TheraDiag, Paris, France) and anticytokine autoantibodies (Millipore, Oakville, Ontario, Canada) using addressable laser bead immunoassays.

\section{RESULTS}

The demographic and clinical parameters of 22 COVID-19 positive $\left(\mathrm{COVID}^{+}\right)$and 20 COVID-19 negative $\left(\mathrm{COVID}^{-}\right)$patients (table 1 ) included an average of 14.1-day stays in ICU and $31 \%$ mortality, but no statistically significant differences between the two cohorts, including the lack of significant differences in the number of thrombotic events requiring therapeutic anticoagulation, platelet counts or platelet counts normalised to the neutrophil counts (to index for severity) (table 1). None of the patients had a history of antecedent APS, systemic lupus erythematosus (SLE) or other conditions associated with APS, nor were there significant differences in other past medical history between $\mathrm{COVID}^{+}$and COVID ${ }^{-}$patients (online supplemental table 1).

\section{Frequency, development and distribution of aCL}

Forty-eight per cent of all the ICU cohort had a positive IgG aCL test (table 1); interestingly, fewer patients had elevated titres of $\operatorname{IgM} \mathrm{aCL}(\mathrm{n}=9,21 \%)$, with only two patients having IgM without IgG. Although more COVID-19 ${ }^{+}$had aCL antibodies, the difference was not statistically significant (table 1); aCL titres were slightly higher among the COVID $-19^{+}$(not statistically significant, (online supplemental table 2) and online supplemental figure 1). Longitudinally testing for anti- $\beta 2-G P 1$ and anti-PS/PT for IgG and IgM, as well as domain 1 anti- $\beta 2-G P 1 \operatorname{IgG}$ revealed only one patient (COVID $-19^{+}$) with positive serology for any of these autoantibodies. This patient seroconverted to IgM anti-PS/PT at days 5-7 of ICU hospitalisation. Table 2 shows the temporal development of the aCL IgG and IgM antibodies stratified by COVID-19 status. Late appearing (beyond 10 days after admission) aCL antibodies were not included in the statistical 
Table 2 Development of ACL $\lg G$ and $\lg M$ over time

\begin{tabular}{lllll}
\hline & & $\begin{array}{l}\text { aCL detected } \\
\text { on admission }\end{array}$ & $\begin{array}{l}\text { aCL developed } \\
\text { within 10 days }\end{array}$ & $\begin{array}{l}\text { Late appearing } \\
\text { aCL } \\
\text { (after 10 days) }\end{array}$ \\
\hline aCL IgG & COVID $^{+}$ & 4 & 9 & 2 \\
positive & COVID $^{-}$ & 3 & 4 & 0 \\
aCL IgM & $\mathrm{COVID}^{+}$ & 1 & 6 & 2 \\
positive & $\mathrm{COVID}^{-}$ & 1 & 1 & 1 \\
\hline
\end{tabular}

Late $\mathrm{aCL}$ was not included in the statistical analyses to avoid survival and availability bias, and is shown here for qualitative assessment. $\mathrm{aCL}$, anticardiolipin antibodies.;

analyses to avoid survival and availability bias. Anti-CL were not associated with age or sex (not shown).

\section{aCL versus disease severity, platelet counts and need for anticoagulation}

Patients positive for aCL IgG demonstrated a consistent trend for worse outcomes in all the measures tested but this did not reach statistical significance after adjusting for multiple comparisons (table 3). These trends remained when analysed separately for COVID $^{+}$and COVID ${ }^{-}$(not shown). aaCL IgG positive patients showed no significant differences in platelet counts, platelet to neutrophil ratio or the need for therapeutic anticoagulation (table 3).

\section{aCL association with ANA, antigen-specific autoantibodies and anti-cytokine autoantibodies}

We tested a broad range of non-APS autoantibodies to understand the autoimmune context of these patients and their potential relationship to APS autoantibodies. Although aCL IgG positivity was not associated with the presence of HEp-2 IFA ANA at a dilution of 1:160, it was significantly associated with higher ANA titres (online supplemental figure 2), $\mathrm{p}=0.03$ ). This trend remained when analysing the $\mathrm{COVID}^{+}$and $\mathrm{COVID}^{-}$ patients separately (data not shown). IgG aCL positivity was also significantly associated with anticytokine autoantibodies, both when analysed for positive or high-positive anticytokine titres ( $p=0.003$ for both, adjusted for multiple comparisons); this was not related to any particular anticytokine autoantibody, although anti-interferon- $\gamma$, anti-IL10 and anti-IL-17f were the most prevalent (online supplemental table 3). When analysing the aCL IgG positive according to their COVID-19 status, the COVID ${ }^{+}$had significantly higher levels of anticytokine autoantibodies than the $\mathrm{COVID}^{-}$(online supplemental table 4). aCL IgG was not associated with antigen-specific autoantibodies, including SLE and myositis-related autoantibodies (not shown).

\section{DISCUSSION}

In the year since the onset of the SARS-CoV2 pandemic, there has been a remarkable surge in publications about one disease, COVID-19, chronicling the clinical onset and outcomes, and a host of biomarkers purported to have related pathophysiological significance (reviewed in references 17 18). The key observation of this study is that patients with positive IgG aCL showed a trend towards more severe disease regardless of whether they were COVID ${ }^{+}$and COVID $^{-}$. That is, while COVID ${ }^{+}$patients showed non-significant trends towards worse respiratory outcomes when compared with $\mathrm{COVID}^{-}$, aCL status had an independent association with disease severity, and did not modulate the outcomes differentially based on COVID status. The pathological significance of aCL seropositivity is unclear since there were no major differences in platelet counts or thrombotic events in the two cohorts. Others have reported a high prevalence of aCL autoantibodies among $\mathrm{COVID}^{+}$patients, but these studies lacked contemporaneous COVID $^{-}$control groups of similar disease severity. ${ }^{6} 151920$

Although aCL tended to associate with COVID $-19^{+}$, they did not associate with the presence of other antigen-specific autoantibodies, although they had a strong association with certain anticytokine autoantibodies, which are reported to neutralise corresponding type I IFNs ability to block SARS-CoV-2 infection in vitro. ${ }^{21}$ Interestingly, some patients had positive $\mathrm{IgG}$ aCL serology on ICU admission (table 2) in the absence of another relevant comorbidity such as APS or SLE (online supplemental table 1). These observations suggest that aCL positivity in the setting of acute severe respiratory illness may be a marker of a unique phenotype with variable temporal expression of aCL and anticytokine antibodies. The temporal dynamic is evidenced by the relatively long time frame from symptom onset to ICU

Table 3 Association between ACL lgG and disease severity, platelet counts and need for anticoagulation

\begin{tabular}{|c|c|c|c|c|}
\hline & Cohort & All & aCL IgG positive & aCL IgG negative \\
\hline & $\mathrm{N}$ & 42 & 20 & 22 \\
\hline Age & Mean $(\mathrm{Cl})$ & $58.2(62.7$ to 54.1$)$ & 55.9 (62.9 to 49$)$ & 60.7 (66.4 to 55$)$ \\
\hline Sex & $\mathrm{N}$ male $(\%)$ & 29/42 (69) & $13 / 20(65)$ & $16 / 22(73)$ \\
\hline Days from symptom onset to ICU & Mean $(\mathrm{Cl})$ & $6(8.3$ to 3.7$)$ & 8.7 (12.8 to 4.6$)$ & 3.4 (5.4 to 1.5$)$ \\
\hline APACHE II on ICU admission & Mean $(\mathrm{Cl})$ & $25.3(27.6$ to 22.9$)$ & $25.7(28.5$ to 22.9$)$ & 24.9 (28.8 to 20.9$)$ \\
\hline Mean of SOFA score for first 3 days & Mean $(\mathrm{Cl})$ & 9.6 (10.7 to 8.5$)$ & 10.6 (12.2 to 9.1$)$ & $8.7(10.3$ to 7$)$ \\
\hline Mean of SOFA score for first 7 days & Mean $(\mathrm{Cl})$ & 8.9 (10.1 to 7.8$)$ & 10 (11.7 to 8.4$)$ & $8(9.5$ to 6.4$)$ \\
\hline ICU days (censored) & Mean (Cl) & $14.1(17.3$ to 10.8$)$ & $16.6(21.9$ to 11.3$)$ & 12.1 (16.5 to 7.6$)$ \\
\hline Death in ICU & $\mathrm{N}(\%)$ & $13 / 42(31)$ & $8 / 20(40)$ & $5 / 22(23)$ \\
\hline Mechanical ventilation days (censored) & Mean $(\mathrm{Cl})$ & 14.4 (18.9 to 10$)$ & $18.2(25.5$ to 10.8$)$ & 11.1 (16.4 to 5.7$)$ \\
\hline Total days of ventilation rescue measures & Mean $(\mathrm{Cl})$ & $2.9(4.3$ to 1.4$)$ & 3.6 (5.6 to 1.5$)$ & $2.3(4.4$ to 0.1$)$ \\
\hline Therapeutic anticoagulation used & $\mathrm{N}(\%)$ & 8 & $4 / 20(20)$ & $4 / 22(18)$ \\
\hline Mean platelet count & Mean $(\mathrm{Cl})$ & 239 (269 to 209$)$ & 268 (321 to 216) & 212 (246 to 179$)$ \\
\hline Mean platelet to neutrophil ratio & Mean (Cl) & 35.2 (42 to 28.4 ) & 34.8 (45.2 to 24.3$)$ & 35.6 (45.4 to 28.9 ) \\
\hline
\end{tabular}

See table 1 for details on the variables shown. There were no statistically significant differences between aCL IgG positive and aCL IgG negative patients for all variables, using ANOVA for continuous variables and Fisher's exact test for categorical variables at $\alpha=0.05$, followed by the false discovery rate at $q=0.05$.

aCL, anticardiolipin; ANOVA, analysis of variance; APACHE, Acute Physiology and Chronic Health Evaluation (score); ICU, intensive care unit; SOFA, sequential organ failure assessment (score) 
admission to the development of IgG aCL (table 3). Our findings highlight the importance of longitudinal monitoring of acutely ill patients. It seems plausible that disparate conclusions in the literature with respect to the significance of APLAs in COVID-19 may relate to arbitrary sampling times and lack of longitudinal follow-up in the setting of dynamic inflammatory diseases.

While some reports have included LAC in their analyses, we did not because LAC is known to be an unreliable biomarker in severe illnesses where $\mathrm{C}$ reactive protein, anticoagulant use and other factors confound its detection. ${ }^{223}$ In this study, we used the anti-PS/ PT test regarded by some as a surrogate for LAC (reviewed in reference 3). However, only one patient developed anti-PS/PT 5-7 days after admission. Further, our observation that no patient had antibodies to $\beta 2$-GP1 (an APS criteria antibody) or to domain $1 \beta 2$-GPI (reportedly higher specificity for APS) argues against the presence of APS in our cohort. In addition, aCL in isolation and/or the depletion of $\beta 2$-GPI reactivity has been associated with the loss of pathogenic thrombosis formation (reviewed in reference 3). In a study of 37 COVID+ acute respiratory disease vs 31 prepandemic (not contemporaneous) acute respiratory disease controls using a sample collected within 48 hours of admission, Frapard et al reported that 37 patients with COVID-19 exhibited more thrombotic events as compared with 31 prepandemic controls but the occurrence of APLA in the two groups was similar. ${ }^{24}$ Using APLA assays similar to ours, Borghi et al reported a low prevalence of APLA in COVID ${ }^{+}$ sera, where the most common target was IgG $\beta 2$-GP1 (15.6\%). ${ }^{20}$ In addition, the primary $\beta 2 \mathrm{GP} 1$ antibody targets were in domains $2-4$ which are less specific for APS. ${ }^{20}$ In agreement with our study, Bertin et $a l^{12}$ and Borghi $e a^{20}{ }^{20}$ concluded that APLA were not associated with major thrombotic events.

The main limitation of our study is the small sample size, although studies using somewhat larger COVID-19 cohorts have reached similar conclusions. ${ }^{120}$ The strengths of our study include its prospective, contemporaneous $\mathrm{COVID}^{-}$cohort with similar severity of disease. Importantly, we tested a broad APLA serological panel longitudinally, providing a more robust assessment of its true prevalence and incidence than in other reported studies; this is particularly relevant for such acutely ill patients with dynamic clinical courses. Finally, our use of an extensive serological panel allowed us to better characterise the broad phenotype associated with aCL.

\author{
Author affiliations \\ ${ }^{1}$ Critical Care, St Michael's Hospital, Toronto, Ontario, Canada \\ ${ }^{2}$ Departments of Medicine and Immunology, University of Toronto, Toronto, Ontario, \\ Canada \\ ${ }^{3}$ Division of Rheumatology, St. Michael's Hospital, Toronto, Ontario, Canada \\ ${ }^{4}$ Keenan Centre for Biomedical Research, Li Ka Shing Knowledge Institute, St \\ Michael's Hospital, Toronto, Ontario, Canada \\ ${ }^{5}$ Interdepartmental Division of Critical Care Medicine, University of Toronto, Toronto, \\ ON, Canada \\ ${ }^{6}$ Cumming School of Medicine, University of Calgary, Calgary, Alberta, Canada
}

Acknowledgements The authors acknowledge the technical assistance of Haiyan Hou, Meifeng Zhang and Emily Walker in the MitogenDx Laboratory at the University of Calgary. We thank Marlene Santos, Gyan Sadhu, Imrana Khalid and Sebastian Duncan, the research coordinators at St Michael's Hospital Critical Care Research Unit. We are grateful to patients and families that have generously consented to the study.

Contributors This report is part of the COLOBILI study (Coronavirus longitudinal biomarkers in lung injury). AB and CDS are principal investigators; MJF, RR and AS are collaborators/coinvestigators and UT is the research lead. RR, MJF, UT and CDS conceived of the study; MJF, UT and RR wrote the manuscript drafts; $A S, A B$ and CDS provided critique and technical guidance; UT performed the data analysis and creation of the figures. All authors edited the manuscript, through to the final version, read and approved the final submission.
Funding St Michael's Hospital Foundation, internal competitive grant to $A B$ and CDS. Autoantibody testing was provided as a gift in kind by MitogenDx (Calgary, $A B$, (anada).

Competing interests MJF is the Director of MitogenDx. MJF is a consultant for and received speaking honoraria from Inova Diagnostics Inc (San Diego, California, USA) and Werfen International (Barcelona, Spain). All the other authors have no disclosures to declare.

Patient and public involvement statement Patients and public were not involved in the design of the study. During the initial phases of the study, we obtained feedback from the patients and their substitute decision makers. Their concerns, questions and preferences were incorporated into improved processes for consent and collection of biological samples. The consent forms have checkboxes with optional aspects of the study, to accommodate different patient preferences. The results of the study will be disseminated in lay versions by St. Michael's Hospital public relations and communications departments for the benefit of the public.

Patient consent for publication Not required.

Ethics approval This is an observational cohort study of patients admitted to St. Michael's Hospital (Toronto, ON, Canada), as approved by the Research Ethics Board (REB\# 20-078).

Provenance and peer review Not commissioned; externally peer reviewed.

Data availability statement All data relevant to the study are included in the article or uploaded as online supplemental information. The datasets used and/or analysed during the current study are available from the corresponding author on reasonable request.

Supplemental material This content has been supplied by the author(s). It has not been vetted by BMJ Publishing Group Limited (BMJ) and may not have been peer-reviewed. Any opinions or recommendations discussed are solely those of the author(s) and are not endorsed by BMJ. BMJ disclaims all liability and responsibility arising from any reliance placed on the content. Where the content includes any translated material, BMJ does not warrant the accuracy and reliability of the translations (including but not limited to local regulations, clinical guidelines, terminology, drug names and drug dosages), and is not responsible for any error and/or omissions arising from translation and adaptation or otherwise.

Open access This is an open access article distributed in accordance with the Creative Commons Attribution Non Commercial (CC BY-NC 4.0) license, which permits others to distribute, remix, adapt, build upon this work non-commercially, and license their derivative works on different terms, provided the original work is properly cited, appropriate credit is given, any changes made indicated, and the use is non-commercial. See: http://creativecommons.org/licenses/by-nc/4.0/.

\section{ORCID iDs}

Uriel Trahtemberg http://orcid.org/0000-0001-9103-2494

Marvin J Fritzler http://orcid.org/0000-0003-1652-6608

\section{REFERENCES}

1 Sevim E, Zisa D, Andrade D, et al. Characteristics of antiphospholipid antibody positive patients in antiphospholipid syndrome alliance for clinical trials and international networking. Arthritis Care Res 2020. doi:10.1002/acr.24468. [Epub ahead of print: 28 Sep 2020]

2 Barbhaiya M, Zuily S, Ahmadzadeh Y, et al. Development of new international antiphospholipid syndrome classification criteria phase I/II report: generation and reduction of candidate criteria. Arthritis Care Res 2020. doi:10.1002/acr.24520. [Epub ahead of print: 30 Nov 2020].

3 Sciascia S, Sanna G, Murru V, et al. Anti-prothrombin (aPT) and antiphosphatidylserine/prothrombin (aPS/PT) antibodies and the risk of thrombosis in the antiphospholipid syndrome. A systematic review. Thromb Haemost 2014;111:354-64.

4 Noordermeer T, Molhoek JE, Schutgens REG, et al. Anti-B2-glycoprotein I and antiprothrombin antibodies cause lupus anticoagulant through different mechanisms of action. J Thromb Haemost 2021;19:1018-28.

5 Kollias A, Kyriakoulis KG, Dimakakos E, et al. Thromboembolic risk and anticoagulant therapy in COVID-19 patients: emerging evidence and call for action. $\mathrm{Br} J$ Haematol 2020;189:846-7.

6 Zuo Y, Estes SK, Ali RA, et al. Prothrombotic autoantibodies in serum from patients hospitalized with COVID-19. Sci Trans/ Med 2020;12:3876.

7 Lammert C, Zhu C, Lian Y, et al. Exploratory study of autoantibody profiling in drug-induced liver injury with an autoimmune phenotype. Hepatol Commun 2020;4:1651-63.

8 Fan BE, Ng J, Chan SSW, et al. COVID-19 associated coagulopathy in critically ill patients: a hypercoagulable state demonstrated by parameters of haemostasis and clot waveform analysis. J Thromb Thrombolysis 2020;50. doi:10.1007/s11239-02002318-x. [Epub ahead of print: 24 Oct 2020].

9 Anka AU, Tahir MI, Abubakar SD, et al. Coronavirus disease 2019 (COVID-19): an overview of the immunopathology, serological diagnosis and management. Scand J Immunol 2021;93:e12998. 


\section{Epidemiology}

10 Pineton de Chambrun M, Frere C, Miyara M. High frequency of antiphospholipid antibodies in critically-ill COVID-19 patients: a link with hypercoagulability? J Intern Med 2020;289:427-9.

11 Showers CR, Nuovo GJ, Lakhanpal A, et al. A Covid-19 patient with complementmediated coagulopathy and severe thrombosis. Pathobiology 2021;88:1-9.

12 Bertin D, Brodovitch A, Beziane A, et al. Anticardiolipin IgG autoantibody level is an independent risk factor for COVID-19 severity. Arthritis Rheumatol 2020;72:1953-5.

13 Mendoza-Pinto C, García-Carrasco M, Cervera R. Role of infectious diseases in the antiphospholipid syndrome (including its catastrophic variant). Curr Rheumatol Rep 2018:20:62-773.

14 Connell NT, Battinelli EM, Connors JM. Coagulopathy of COVID-19 and antiphospholipid antibodies. J Thromb Haemost 2020;10.1111:jth. 14893.

15 El Hasbani G, Taher AT, Jawad A, et al. COVID-19, antiphospholipid antibodies, and catastrophic antiphospholipid syndrome: a possible association? Clin Med Insights Arthritis Musculoskelet Disord 2020;13:1-8. doi:10.1177/1179544120978667

16 Radic M, Pattanaik D. Cellular and molecular mechanisms of anti-phospholipid syndrome. Front Immunol 2018;9:969.
17 Lauper K, Bijlsma JWJ, Burmester GR. Trajectories of COVID-19 information in the Annals of the rheumatic diseases: the first months of the pandemic. Ann Rheum Dis 2021;80:26-30.

18 Carvalho T, Krammer F, Iwasaki A. The first 12 months of COVID-19: a timeline of immunological insights. Nat Rev Immunol 2021;21:245-56.

19 Tang N. Response to "Lupus anticoagulant is frequent in patients with Covid-19" (JTH-2020-00483). J Thromb Haemost 2020;18:2065-6.

20 Borghi MO, Beltagy A, Garrafa E, et al. Anti-Phospholipid antibodies in COVID-19 are different from those detectable in the anti-phospholipid syndrome. Front Immunol 2020;11:584241.

21 Bastard P, Rosen LB, Zhang Q, et al. Autoantibodies against type I IFNs in patients with life-threatening COVID-19. Science 2020;370:eabd4585.

22 Gooding R, Myers B, Salta S. Lupus anticoagulant in patients with Covid-19. N Eng/ J Med 2020;383:1893.

23 Gkrouzman E, Barbhaiya M, Erkan D, et al. Reality check on antiphospholipid antibodies in COVID-19-Associated coagulopathy. Arthritis Rheumatol 2021;73:173174.

24 Frapard T, Hue S, Rial C. Antiphospholipid antibodies and thrombosis in patients with COVID-19. Arthritis Rheumatol 2020;Online ahead of print. 